\title{
Gas Pressure Measurement Device and Medical Vacuum Design
}

\author{
Tatiya Padang Tunggal ${ }^{1}$, Alfana Sanjaya ${ }^{2}$, Hendro Agus Widodo ${ }^{3}$, Kunal Kunal ${ }^{4}$, Phong Thanh Nguyen \\ ${ }^{1,2}$ Department of Electrical Engineering, Universitas Muhammadiyah Yogyakarta, Yogyakarta, Indonesia \\ ${ }^{3}$ Politeknik Perkapalan Negeri Surabaya, Surabaya, Indonesia \\ ${ }^{4}$ School of Information, Communication \& Technology, Indraprastha University, Delhi, India \\ ${ }^{5}$ Director, Department of Project Management, Ho Chi Minh City Open University, Vietnam \\ tatiyapt@umy.ac.id ${ }^{1}$, alfanasanjaya@umy.ac.id ${ }^{2}$, hendro.aw@ppns.ac.id ${ }^{3}$, Kunal.karn007@gmail.com ${ }^{4}$, \\ phong.nt@ou.edu.vn ${ }^{5}$
}

\begin{abstract}
Two methods are used in a digital pressure meter available in the market, namely positive pressure, and negative pressure. The positive one is used to measure the air pressure on a sphygmomanometer and medical gas pressure at an outlet in the treatment room so that operators can easily check medical gas pressure for the safety of the patient, or they can routinely check to find out how much pressure of the medical gas. Based on the background, the research aimed to design a digital pressure meter equipped with a medical gas measurement mode so that the device can be used to calibrate the sphygmomanometer, suction pump, and measure the medical gas pressure available at the medical gas outlet in each treatment room.
\end{abstract}

Keywords - sphygmomanometer, pressure meter, microcontroller

\section{INTRODUCTION}

Digital Pressure Meter is a device designed to measure pressure from medical devices in liquid or gas form to help calibrate medical devices, in this case, the calibration of the sphygmomanometer and the suction pump. The way this device works is by converting the value of the pressure sensor to be changed and displayed on the LCD.

Medical gas is a gas with special specifications used for medical services in health facilities. Types of Medical Gas used in health care facilities include Oxygen (O2), Nitros Oxide (N2O), Nitrogen (N2), Carbon dioxide (CO2), Cyclopropane (C3H6), Helium (He), Compressed Air (Compressed Air), and Gas Mixture. It is a life-supporting element that has a direct effect on maintaining patients' lives. Therefore, in the part where medical gas is used, it must be clean, have high purity, and be available with stable pressure.

Several researchers have researched monitoring gas pressure. Miyazaki et al. investigated the gas pressure monitoring system for GIL using an optical fiber gas density sensor. An optical fiber gas pressure monitoring system was developed with a new gas density sensor to detect gas leak insulation from the Gas Insulated Transmission Line (GIL) [1]. Graber and Pradhan examined SF6 pressure levels in metal-enclosed switchgear to detect gas leaks using a pressure sensor [2]. Lung-Jieh Yang and A-Fu Kao monitored gas permeation in PDMS using a pressure sensor on-site. The new methodology for detecting gas leaks and the corresponding diffusion coefficient utilized PDMS instead of Pyrex \#7740 glass to seal the back of the V-groove from the pressure sensor chip [3].

Hao et al. studied the zero-temperature coefficient of a gas-sealed pressure sensor using mechanical temperature compensation. The system used a pressure sensor sealed by $\mathrm{Au}-\mathrm{Au}$ diffusion bonds in nitrogen at a pressure of $100 \mathrm{kPa}$ and integrated with a platinum resistor-based temperature sensor for monitoring human activity [4]. Mishra conducted leak monitoring in low-pressure gas pipelines in real-time. An experimental study was carried out in real-time monitoring of pressure and flow variations. The valve arrangement was used to monitor the effects of leakage on pressure parameters and city gas flow [5]. Ravula et al. conducted an experimental validation of leak detection and water integration in low-pressure gas pipes using pressure and flow measurements. In underground low-pressure gas distribution pipes, groundwater entered the pipeline through cracks. It was known as the problem of water entry and occurred especially in the rainy season when the water level was high [6].

Kumar and Pathak studied wireless monitoring of volatile organic compounds/water vapor/gas pressure/temperature using RF transceivers. The development and characterization of a wireless pressure monitoring system (WPMS) utilized integrated radio frequency (RF) transceivers for applications such as monitoring variations in the pressure of given gas vapor, volatile organic compounds (VOC), and water vapor [7]. Chao et al. investigated a smart gas pressure regulator control system [8]. A smart gas regulator control system was an innovation in a situation that constantly improved the precision and management requirements of gas equipment control systems, which`h integrated and optimized the production and operation of information-based systems and improved production management "cloud platforms". The SF6 had been widely applied in isolated gas switchgear because of its excellent insulation and arc performance [9].

Several other researchers have researched gas monitoring using a microcontroller. Unnikrishnan et al. investigated the LPG leak detection and monitoring system. The system 
consisted of a weight sensor, a gas sensor, a PIC microcontroller, a buzzer, and an LCD [10]. Luo et al. designed a wireless monitoring system for gas emergency repairs. The system consisted of wireless nodes and terminal software. Wireless nodes were used to collect gas concentration, temperature, humidity, wind speed and wind direction in real-time, and send data to the command terminal [11]. A real-time air quality monitoring system for the Bangladesh perspective based on the Internet of Things was investigated by Ahmed, Banu, and Paul. The system consisted of an Intel type microcontroller, a gas sensor consisting of MQ-2, MQ-3, and MQ-7, a buzzer, and an LED [12].

Parmar, Lakhani, and Chattopadhyay investigated the IoT-based low-cost air pollution monitoring system consisting of gas sensors comprising the MQ-7 sensor and the MQ-135 sensor, the Raspberry Pi, and the Nucleo F401RE ARM® 32-bit Cortex ${ }^{\circledR}-M 4$ CPU [13]. Ilie and Vaccaro designed smart gas detection systems in natural gas storage areas. The system consisted of an Arduino microcontroller, gas sensors, namely an MQ-4 sensor and an MQ-811 sensor, a temperature sensor, an air pressure sensor, and a $\mathrm{pH}$ sensor [14]. Keshamoni and Hemanth conducted gas level monitoring, reservation of gas leak detectors through IoT system) consisting of weight sensors, temperature sensors, gas sensors, an AT89S52 microcontroller, and an IoT ESP 8266 [15].

Pavani and Rao proposed real-time pollution monitoring using Wireless Sensor Networks [16], while Di Lecce et al. proposed an online wastewater monitoring system using a solid-state sensor. Management of water and wastewater monitoring is a very important task for environmental control operations within the framework of the Adaptive Water Management policy which is enforced by current EU legislation [17]. Spirjakin, Baranov, and Akbari investigated an energy harvesting algorithm for wireless multi-sensor gas platforms. Several sensors with high priority monitoring tasks within the scope of the Smart City and Smart Home applications were required to successfully detect leaks of various gases and their different concentrations in air quality control [18].

The neural network approach to safety monitoring applications was investigated by Marinkovic et al. A single artificial neural network was used to determine gas concentrations based on sensor array measurements, which worked at the same time as temperature compensation and the effect of humidity on the sensor output [19]. Rossi and Brunelli observed gas sensing in an unmanned vehicle comprising a UAV Quadrotor and a gas sensor [20]. The embedded hardware prototype for gas detection and monitoring systems on the android mobile platform was investigated by Kurzekar, Arora, and Shrestha. The system consisted of LPG gas sensors, an ATMEGA16 microcontroller, and Bluetooth [21].

A sphygmomanometer is a device used to measure blood pressure that works manually or automatically in pumping or reducing pressure on cuffs with a non-invasive system. There are two types of blood pressure, namely systolic (upper limit) and diastolic (lower limit). Systolic pressure is 95 to 140
$\mathrm{mmHg}$, while diastolic pressure is 60 to $90 \mathrm{mmHg}$. The suction pump, in general, is one of the ways to clean the blocked airway due to secretions/fluid/mucus so that the gas can flow unobstructed. Suctioning must be done appropriately, correctly, and safely.

Medical treatment using a sphygmomanometer \& suction pump must be controlled, including how often the device is an error or damaged. The high level of performance makes the device in an unfavorable condition so that there is a need for preventive maintenance applied according to the schedule and the calibration of the device to monitor in more detail the performance of the device to work perfection to reduce the risk of errors in medical treatment on patients. The creation of a Digital Pressure and Vacuum Meter device with medical gas pressure measurement is expected to assist the operator in the sphygmomanometer calibration process and suction pump to improve the accuracy of the device and help the operator to check the medical gas pressure given to the patient, do routine inspection, and examination after carry out Medical Gas Installation.

\section{METHOD}

Figure 1 illustrates the system block diagram showing that when the power button is pressed, all circuits get voltage including the pressure sensor, and the device is ready to operate. The measurement modes available on the menu are air pressure, vacuum pressure, and oxygen pressure. The display shows $0 \mathrm{mmHg}$ before giving pressure. The incoming pressure resulted from the manual pumping is received by the pressure sensor and converted to an analog voltage. The voltage is processed by an analog signal conditioning circuit before entering the internal ADC available in the ATmega8 Microcontroller IC [22] [23] and the microcontroller converts the analog to the digital voltage for further processing. The data from the processing will be processed by ATMega8 [24] [25], stored, and displayed on the LCD.

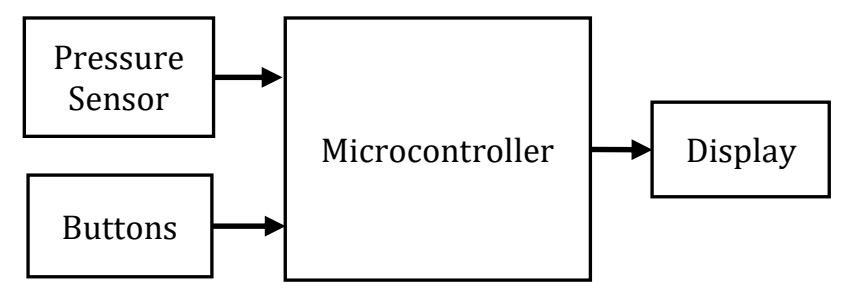

Fig. 1. System block diagram

\section{a. System workflow program}

Figure 2 displays the system workflow diagram. When the device is in a ready state, the LCD displays the mode selection, namely measurement or reading data storage. When the measurement mode is selected, measurements can be performed.

The result of the process appears without a delay. When the enter button is pressed, the pressure detected by the sensor will be processed by the microcontroller to retrieve data. The calculation results from the ADC will be displayed to the LCD. 


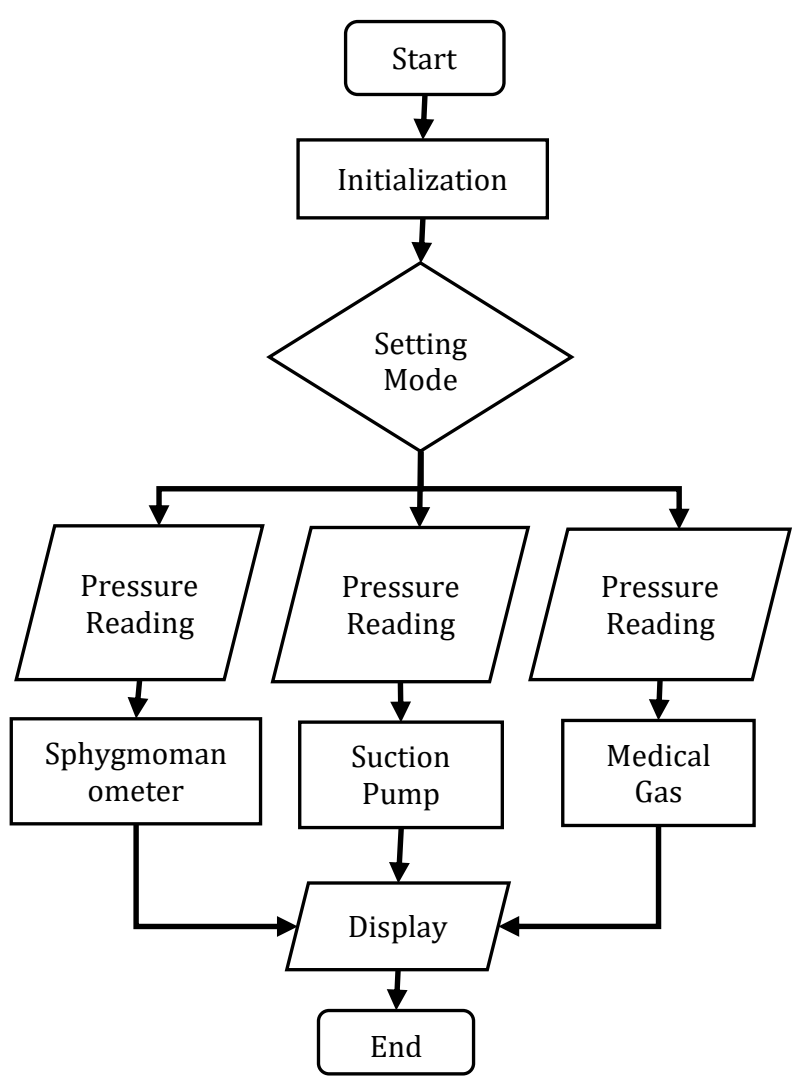

Fig. 2. System workflow diagram

\section{b. System hardware}

As shown in Figure 3, the circuit is composed of several circuit blocks with installed components according to their functions, and are electrically combined to become a system that is suitable for module design. There are several blocks installed in this system; (a) System minimum [31], [32], (b) sensor circuit, and (c) 16x2 LCD.

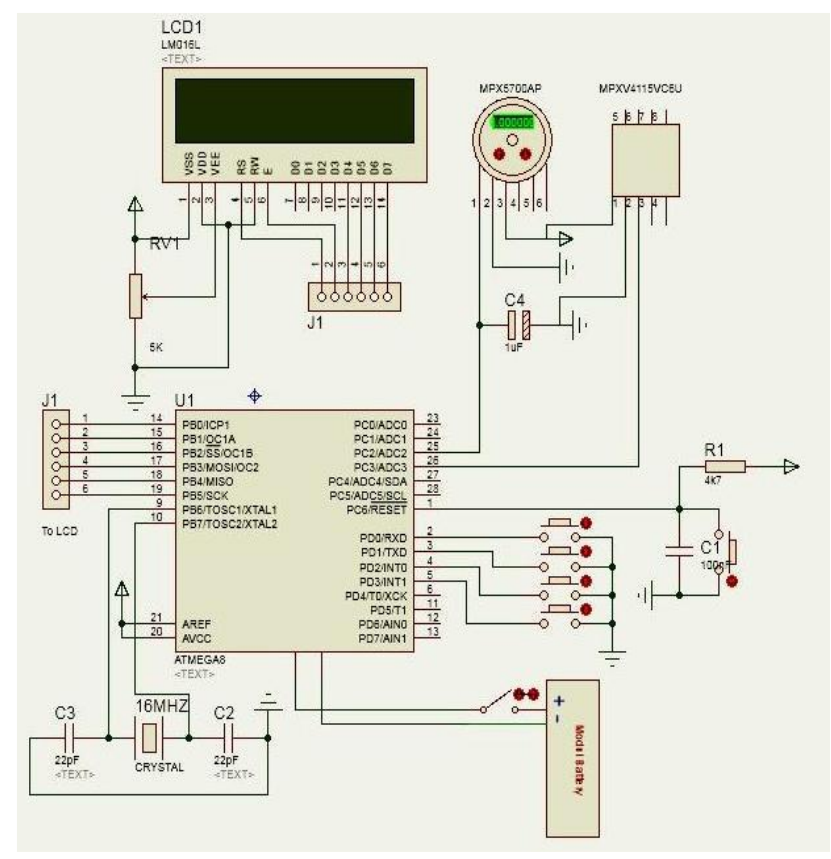

Fig. 3. System schematic diagram

\section{c. System analysis}

The system parameters analyzed to find out the system performance are Average, the value or result of the division of the amount of data taken or measured by the amount of data retrieval or the number of measurements, Deviation, the difference from the average value of the desired price with the measured value, Error, the difference between the mean of each data, and Standard deviation, the value that indicates the level (degree) of variation in data groups or standard measures of deviation from the average. Uncertainty is doubt that arises in each outcome. The measurement is commonly referred to as data precision with other data.

\section{III.RESULT AND DISCUSSION}

\section{a. Pressure sensor test}

The pressure sensor used MPX5700AP type for positive pressure and MPXV4115VC6U type for negative pressure. Positive pressure in question was air pressure and oxygen pressure, while the negative pressure in question was vacuum pressure.

The barometric pressure for the pressure sensor is shown in Table 1. From the table, it is seen that each pressure measurement of $50 \mathrm{mmHg}$ is measured by the sensor output. When the pressure is measured $50 \mathrm{mmHg}$, the sensor output is 0.86671 volts. Data collection for pressure starts from 50 $\mathrm{mmHg}$ up to $250 \mathrm{mmHg}$.

TABLE I. PRESSURE BASED SENSOR OUTPUT FOR BAROMETRIC PRESSURE

\begin{tabular}{|c|c|c|}
\hline No. & Pressure (mmHg) & Output Sensor (Volt) \\
\hline 1 & 50 & 0.86671 \\
\hline 2 & 100 & 0.9108 \\
\hline 3 & 150 & 0.9527 \\
\hline 4 & 200 & 0.995 \\
\hline 5 & 250 & 1.036 \\
\hline
\end{tabular}

Measurement of oxygen pressure using a pressure sensor is shown in Table 2. From the table, it can be seen that the measurement of oxygen pressure is measured from a pressure of 100 to a pressure of 500 with a range of 100 . When the pressure is $100 \mathrm{mmHg}$, the output of the pressure sensor is 1.458 volts. And for a pressure of $500 \mathrm{mmHg}$, the output of the pressure sensor is 3.979 volts.

TABLE II. PRESSURE BASED SENSOR OUTPUT FOR OXYGEN PRESSURE

\begin{tabular}{|c|c|c|}
\hline No. & Pressure (mmHg) & Output Sensor (Volt) \\
\hline 1 & 100 & 1.458 \\
\hline 2 & 200 & 2.089 \\
\hline 3 & 300 & 2.718 \\
\hline 4 & 400 & 3.349 \\
\hline 5 & 500 & 3.979 \\
\hline
\end{tabular}


The measurement of vacuum pressure using a pressure sensor is shown in Table 3. From the table, it is seen that the measurement of oxygen pressure is measured from -100 to 500 with a range of 100 . When the pressure is $-100 \mathrm{mmHg}$ the output of the pressure sensor is 4,059 volts. And for pressures of $-500 \mathrm{mmHg}$, the output of the pressure sensor is 3.060 volts.

TABLE III. PRESSURE BASED SENSOR OUTPUT FOR VACUUM PRESSURE

\begin{tabular}{|c|c|c|}
\hline No. & Pressure (mmHg) & Output Sensor (Volt) \\
\hline 1 & -100 & 4.059 \\
\hline 2 & -150 & 3.809 \\
\hline 3 & -200 & 3.559 \\
\hline 4 & -250 & 3.309 \\
\hline 5 & -300 & 3.060 \\
\hline
\end{tabular}

\section{b. Sphygmomanometer Measurement Results}

Subsequent experiments tested the entire sphygmomanometer shown in Table 4. From the table, it appears that measurements were taken from pressures of 50 $\mathrm{mmHg}$ to $250 \mathrm{mmHg}$. When the pressure is $50 \mathrm{mmHg}$ then the Standard average $(\mathrm{mmHg})$ 50.26, Tested average $(\mathrm{mmHg}) 51.21$, Error 1.88, and the Standard deviation 0.204. And for the pressure of $250 \mathrm{mmHg}$, the Standard average $(\mathrm{mmHg})$ is 250.26 , Tested average $(\mathrm{mmHg})$ is 250.55 , Error -0.11 , and the Standard deviation is 0.054 .

TABLE IV. OVERALL AVERAGE TEST RESULT OF SPHYGMOMANOMETER

\begin{tabular}{|l|l|l|l|l|}
\hline $\begin{array}{l}\text { Expected } \\
\text { pressure } \\
(\mathrm{mmHg})\end{array}$ & $\begin{array}{l}\text { Standard } \\
\text { average } \\
(\mathrm{mmHg})\end{array}$ & $\begin{array}{l}\text { Tested } \\
\text { average } \\
(\mathrm{mmHg})\end{array}$ & Error & $\begin{array}{l}\text { Standard } \\
\text { deviation }\end{array}$ \\
\hline 50 & 50.26 & 51.21 & 1.88 & 0.204 \\
\hline 100 & 100.3 & 99.15 & -1.16 & 99.15 \\
\hline 150 & 150.2 & 149.7 & -0.28 & 0.075 \\
\hline 200 & 200.4 & 199.6 & -0.43 & 0.089 \\
\hline 250 & 250.26 & 250.55 & -0.11 & 0.054 \\
\hline
\end{tabular}

\section{c. Suction Pump Measurement Results}

Subsequent experiments tested the entire Suction Pump Measurement shown in Table 5. From table, it appears that measurements were taken from pressures of $100 \mathrm{mmHg}$ to $350 \mathrm{mmHg}$. When the pressure is $100 \mathrm{mmHg}$, then the Standard average $(\mathrm{mmHg}) 92.45$, Tested average $(\mathrm{mmHg})$ 93.14, Error 0.74, and Standard deviation 0.32. And for 350 $\mathrm{mmHg}$ pressure, the Standard average $(\mathrm{mmHg}) 341.48$, Tested average $(\mathrm{mmHg}) 343.68$, Error 0.64, and Standard deviation 0.116 .

\section{d. Measurement Results of the Oxygen pressure}

Subsequent experiments tested the overall oxygen pressure shown in Table 6. From the table, it appears that measurements were taken from pressures of $100 \mathrm{mmHg}$ to $600 \mathrm{mmHg}$. When the pressure is $-100 \mathrm{mmHg}$ then the Standard average $(\mathrm{mmHg}) 100$, Tested average $(\mathrm{mmHg})$ 0.98, Error -1.4, and the Standard deviation 0.081. And for a pressure of $600 \mathrm{mmHg}$, the Standard average $(\mathrm{mmHg}) 600$, Tested average (mmHg) 598.9, Error -0.18 , and Standard deviation 0.15 .

TABLE V. OVERALL AVERAGE TEST RESULT OF SUCTION PUMP

\begin{tabular}{|l|l|l|l|l|}
\hline $\begin{array}{l}\text { Expected } \\
\text { pressure } \\
(\mathrm{mmHg})\end{array}$ & $\begin{array}{l}\text { Standard } \\
\text { average } \\
(\mathrm{mmHg})\end{array}$ & $\begin{array}{l}\text { Tested } \\
\text { average } \\
(\mathrm{mmHg})\end{array}$ & Error & $\begin{array}{l}\text { Standard } \\
\text { deviation }\end{array}$ \\
\hline 100 & 92.45 & 93.14 & 0.74 & 0.32 \\
\hline 150 & 147.56 & 148.06 & 0.33 & 0.194 \\
\hline 200 & 196.48 & 196.56 & 0.03 & 0.172 \\
\hline 250 & 242.86 & 242.98 & 0.048 & 0.331 \\
\hline 300 & 290 & 290.33 & 0.11 & 0.581 \\
\hline
\end{tabular}

TABLE VI. OVERALL AVERAGE TEST RESULT OF OXYGEN PRESSURE TEST.

\begin{tabular}{|l|l|l|l|l|}
\hline $\begin{array}{l}\text { Expected } \\
\text { pressure } \\
(\mathrm{mmHg})\end{array}$ & $\begin{array}{l}\text { Standard } \\
\text { average } \\
(\mathrm{mmHg})\end{array}$ & $\begin{array}{l}\text { Tested } \\
\text { average } \\
(\mathrm{mmHg})\end{array}$ & Error & $\begin{array}{l}\text { Standard } \\
\text { deviation }\end{array}$ \\
\hline 100 & 100 & 0.98 & -1.4 & 0.081 \\
\hline 200 & 200 & 198.7 & -0.65 & 0.075 \\
\hline 300 & 300 & 299.1 & -0.3 & 0.288 \\
\hline 400 & 400 & 388.3 & -3.03 & 1.289 \\
\hline 500 & 500 & 498.3 & -0.34 & 0.509 \\
\hline 600 & 600 & 598.9 & -0.18 & 0.15 \\
\hline
\end{tabular}

\section{IV.CONCLUSION}

The device the researcher studied can measure pressure on the sphygmomanometer, suction pump, and medical gas pressure. It displays the pressure output voltage working after getting input through MPX5700AP and MPXV4115VC6U sensors, which are then processed by a microcontroller and produce a pressure and voltage sensor output displayed on the LCD. After performing measurements and error analysis, it is found that the device meets the standard with the following reasons; (a) The greatest error rate of the sphygmomanometer pressure is $1.88 \%$ with a deviation of 1.0 , (b) The greatest error rate of the suction pump pressure is $0.74 \%$ with a deviation of 0.69 , and (c) The highest error rate of the oxygen gas pressure is $-3.08 \%$ with a deviation of 0.13 .

\section{REFERENCES}

[1] A. Miyazaki, M. Yagi, S. Kobayashi, H. Nishima, Y. Nakura, and H. Higashi, "Gas pressure monitoring system for GIL using fiberoptic gas density sensors," IEEJ Trans. Power Energy, vol. 119, no. 4, pp. 451-457, 1999.

[2] L. Graber and M. K. Pradhan, "Monitoring the $\mathrm{SF}<\inf >6</$ inf $>$ pressure level in metal-enclosed switchgear to detect gas leakages," in 2008 International Conference on Condition Monitoring and Diagnosis, 2008, pp. 357-362. 
[3] Lung-Jieh Yang and A-Fu Kao, "Gas permeation in PDMS monitored by on-site pressure sensors," in 2010 IEEE 5th International Conference on Nano/Micro Engineered and Molecular Systems, 2010, pp. 352-355.

[4] X. C. Hao, Y. G. Jiang, H. Takao, K. Maenaka, T. Fujita, and K. Higuchi, "Zero temperature coefficient gas-sealed pressure sensor using mechanical temperature compensation," in 2011 16th International Solid-State Sensors, Actuators and Microsystems Conference, 2011, pp. 116-119.

[5] H. Mishra, P. Karkulali, A. Ukil, and J. Dauwels, "Testbed for realtime monitoring of leak in low pressure gas pipeline," in IECON 2016 - 42nd Annual Conference of the IEEE Industrial Electronics Society, 2016, pp. 459-462.

[6] S. R. Ravula, S. C. Narasimman, L. Wang, and A. Ukil, "Experimental Validation of Leak and Water-Ingression Detection in Low-Pressure Gas Pipeline Using Pressure and Flow Measurements," IEEE Sens. J., vol. 17, no. 20, pp. 6734-6742, Oct. 2017.

[7] A. Kumar and N. P. Pathak, "Wireless Monitoring of Volatile Organic Compounds/Water Vapor/Gas Pressure/Temperature Using RF Transceiver," IEEE Trans. Instrum. Meas., vol. 67, no. 9, pp. 2223-2234, Sep. 2018

[8] L. Chao, C. Lisheng, L. Jinfeng, P. Guangjuan, and Z. Ruizhi, "Intelligent gas pressure regulator control system," in 2017 29th Chinese Control And Decision Conference (CCDC), 2017, pp. 2723-2728.

[9] K. Liu, S. Ji, L. Zhong, X. Xue, L. Zhu, and Y. Wang, "The mechanism of $\mathrm{SF}<\mathrm{inf}>6</ \mathrm{inf}>$ decomposition characteristics under partial discharge at different gas pressures and voltage," in 2016 IEEE International Power Modulator and High Voltage Conference (IPMHVC), 2016, pp. 141-146.

[10] S. Unnikrishnan, M. Razil, J. Benny, S. Varghese, and C. V. Hari, "LPG monitoring and leakage detection system," in 2017 International Conference on Wireless Communications, Signal Processing and Networking (WiSPNET), 2017, vol. 2018-Janua, pp. 1990-1993.

[11] Q. Luo, X. Guo, Y. Wang, and X. Wei, "Design of wireless monitoring system for gas emergency repairing," in 2016 Chinese Control and Decision Conference (CCDC), 2016, pp. 3624-3629.

[12] M. M. Ahmed, S. Banu, and B. Paul, "Real-time air quality monitoring system for Bangladesh's perspective based on Internet of Things," in 2017 3rd International Conference on Electrical Information and Communication Technology (EICT), 2017, vol. 2018-Janua, no. December, pp. 1-5.

[13] G. Parmar, S. Lakhani, and M. K. Chattopadhyay, "An IoT based low cost air pollution monitoring system," in 2017 International Conference on Recent Innovations in Signal processing and Embedded Systems (RISE), 2017, vol. 2018-Janua, pp. 524-528.

[14] A. M. C. Ilie and C. Vaccaro, "Design of a smart gas detection system in areas of natural gas storage," in 2017 IEEE International Geoscience and Remote Sensing Symposium (IGARSS), 2017, pp. 5954-5957.

[15] K. Keshamoni and S. Hemanth, "Smart Gas Level Monitoring, Booking \&amp; Gas Leakage Detector over IoT," in 2017 IEEE 7th International Advance Computing Conference (IACC), 2017, pp. $330-332$.

[16] M. Pavani and P. T. Rao, "Real time pollution monitoring using Wireless Sensor Networks," in 2016 IEEE 7th Annual Information Technology, Electronics and Mobile Communication Conference (IEMCON), 2016, pp. 1-6.

[17] V. Di Lecce, D. Petruzzelli, D. Soldo, and A. Quarto, "Online wastewater monitoring system using solid state sensor," in 2016 IEEE Workshop on Environmental, Energy, and Structural Monitoring Systems (EESMS), 2016, pp. 1-5.
[18] D. Spirjakin, A. M. Baranov, and S. Akbari, "Energy harvesting algorithms for wireless multi-sensor gas platform," in 2016 IEEE Workshop on Environmental, Energy, and Structural Monitoring Systems (EESMS), 2016, pp. 1-6.

[19] Z. Marinkovic, A. Atanaskovic, M. G. Xibilia, C. Pace, M. Latino, and N. Donato, "A neural network approach for safety monitoring applications," in 2016 IEEE Sensors Applications Symposium (SAS), 2016, pp. 1-5

[20] M. Rossi and D. Brunelli, "Gas Sensing on Unmanned Vehicles: Challenges and Opportunities," in 2017 New Generation of CAS (NGCAS), 2017, no. Dii, pp. 117-120.

[21] R. Kurzekar, H. Arora, and R. Shrestha, "Embedded Hardware Prototype for Gas Detection and Monitoring System in Android Mobile Platform," in 2017 IEEE International Symposium on Nanoelectronic and Information Systems (iNIS), 2017, vol. 2018Febru, pp. 6-10.

[22] R. Kumar and A. N. Khalkho, "Design and implementation of metal detector using DTMF technology," in 2016 International Conference on Signal Processing, Communication, Power and Embedded System (SCOPES), 2016, vol. VI, no. July, pp. 368-371.

[23] B. K. Mansingh, S. Karthik, and D. Chandrakumar, "C.A.D.F.I.R.E control and automation of domestic fuel by incorporating relay and emergency alarms," in 2013 International Conference on Green Computing, Communication and Conservation of Energy (ICGCE), 2013, pp. 485-487.

[24] A. Mandal, S. Panda, and A. Goswami, "Driving a Charged Coupled Device (CCD) by microcontroller for LIBS based application," in 2018 International Symposium on Devices, Circuits and Systems (ISDCS), 2018, no. Ccd, pp. 1-5.

[25] Z. Raza, S. Ashraf, K. Liaquat, and H. Kashif, "Monitoring of soldier's health and transmission of secret codes," in 2016 Sixth International Conference on Innovative Computing Technology (INTECH), 2016, pp. 349-354.

[26] E. Ebert, H. Kruger, H. Ewald, M. Rabe, and N. A. Damaschke, "Comparison of two variants of a novel setup for real time high resolution UV-LED absorption spectroscopy," in 2015 9th International Conference on Sensing Technology (ICST), 2015, vol. 2016-March, pp. 430-433.

[27] L. C. L. Landicho, I. R. Magbalon, and C. P. S. Reyes, "A wireless electrocardiogragphy in superintending cardiac rate extremes with global positioning capability to remotely localize specimen," in 2015 IEEE International Conference on Control System, Computing and Engineering (ICCSCE), 2015, no. November, pp. 141-145.

[28] W. Reshmi, R. K. Sundaram, and M. R. Kumar, "Sensor unit for waste management: A better method for frequent data updating system," in 2014 International Conference on Science Engineering and Management Research (ICSEMR), 2014, pp. 1-5.

[29] C. V. A. Satwik, L. P. Kumar, K. Vineeth, and K. N. Pillai, "Intelligent Road Management System for Daily Transit," in 2018 International Conference on Communication and Signal Processing (ICCSP), 2018, pp. 0523-0526.

[30] Z. Bai, X. Chen, and J. Li, "A miniaturized single-chip oximetry module utilizing reflectance photoplethysmography," in 2017 10th International Congress on Image and Signal Processing, BioMedical Engineering and Informatics (CISP-BMEI), 2017, pp. 1-5.

[31] S. Kokare, R. Shastri, and S. Kolhar, "Line Follower with Obstacle Information System Using ZigBee," in 2018 Fourth International Conference on Computing Communication Control and Automation (ICCUBEA), 2018, pp. 1-5.

[32] M. S. Bin Mostafa, A. K. M. Masum, M. S. Uddin, M. K. A. Chy, and S. M. T. Reza, "Amphibious Line following Robot for Product Delivery in Context of Bangladesh," in 2019 International Conference on Electrical, Computer and Communication Engineering (ECCE), 2019, pp. 1-6. 